\title{
Review
}

\section{Coronavirus disease 2019 (COVID-19) in long-term care facilities: A review of epidemiology, clinical presentations, and containment interventions}

\author{
Cameron G. Gmehlin BA (1) and L. Silvia Munoz-Price MD, PhD (1) \\ Division of Infectious Diseases, Department of Medicine, Medical College of Wisconsin, Milwaukee, WI
}

\begin{abstract}
Long-term care facilities (LTCFs) and their populations have been greatly affected by the coronavirus disease 2019 (COVID-19) pandemic. In this review, we summarize the literature to describe the current epidemiology of COVID-19 in LTCFs, clinical presentations and outcomes in the LTCF population with COVID-19, containment interventions, and the role of healthcare workers in SARS-CoV-2 transmission in these facilities.
\end{abstract}

(Received 17 August 2020; accepted 6 October 2020; electronically published 26 October 2020)

\section{Background}

The severe acute respiratory syndrome coronavirus 2 (SARS-CoV2) virus was first identified in Wuhan, China, in December 2019 and has since spread widely across the globe; the World Health Organization (WHO) declared it a global pandemic in March of this year. ${ }^{1,2}$ As more patients became ill with the disease, clinicians recognized that coronavirus disease 2019 (COVID-19) disproportionately affects the elderly, in particular long-term care facility (LTCF) residents. ${ }^{3,4}$ As of July 30, 2020, there have been 4,339,997 confirmed cases of COVID-19 and 148,866 associated fatalities in the United States. ${ }^{5}$ Although LTCF residents only make up 3.5\% of all COVID-19 cases, this population has contributed to $64.9 \%$ of total mortalities due to COVID- $19 .{ }^{6}$ A similar situation is occurring in other countries. ${ }^{7,8}$ In this review, we have synthesized the epidemiology of COVID-19 in LTCFs, clinical presentations and outcomes in this population, containment interventions, and the role of LTCF healthcare workers in SARS-CoV-2 transmission.

\section{Literature review methods}

We examined relevant published studies in Medline and PubMed using the following key terms: COVID-19, SARS-CoV-2, assisted living, group home, and memory care. We also reviewed current Centers for Disease Control (CDC) and Centers for Medicare and Medicaid Services (CMS) COVID-19 guidelines for LTCFs.

\footnotetext{
Author for correspondence: Silvia Munoz-Price, E-mail: smunozprice@mcw.edu Cite this article: Gmehlin CG and Munoz-Price LS. (2022). Coronavirus disease 2019 (COVID-19) in long-term care facilities: A review of epidemiology, clinical presentations, and containment interventions. Infection Control \& Hospital Epidemiology, 43: 504-509, https://doi.org/10.1017/ice.2020.1292
}

\section{Epidemiology}

In LTCFs that have COVID-19 cases, SARS-CoV-2 positivity rates can vary widely (Table 1 ), with an average positivity rate of $\sim 37 \%$. Studies that examined COVID-19 outbreaks in LTCFs had higher attack rates on average (42.9\%), ${ }^{9-18}$ but 3 studies surveyed nursing homes without regard to outbreak status and found a SARS-CoV-2 prevalence between $6 \%$ and $23 \%{ }^{19-21}$ The highest SARS-CoV-2 positivity rate recorded was by McMichael et $\mathrm{al}^{15}$ at $77 \%$, although this was a cumulative attack rate over a month.

Numerous studies have attempted to identify associations between LTCF characteristics and COVID-19 incidence. Studies using the CMS Five-Star Quality Rating System reported that increased nursing-home size and degree of occupancy appear strongly associated with higher likelihood of having at least 1 resident with COVID-19. ${ }^{21-24}$ LTCF resident demographics also influence the probability of having at least 1 COVID-19 case. Higher proportion of African-American residents, lower proportion of white residents, and higher Medicaid share were all associated with higher numbers of COVID-19 cases. $^{23-25}$ Staffing levels and CMS staffing rating of LTCFs may also affect COVID-19 spread. In California, lower nurse staffing hours per resident per day and lower Five-Star nursing score were both associated with increased risk of COVID-19 cases in the facilities. ${ }^{26}$ Similarly, in Connecticut, decreased nursing hours were associated with an increased number of COVID-19 cases. ${ }^{27}$ Among facilities with at least 1 death attributed to COVID-19, higher numbers of nursing hours were protective. ${ }^{27}$ Other factors associated with greater incidence of COVID-19 included higher levels of LTCF resident independence, higher number of CMS health deficiencies, and for-profit status. ${ }^{21,23-26} \mathrm{Li}$ et al found that nurse staffing, CMS Five-Star rating, and concentrations of Medicaid and racial/ethnic minorities in the facilities were associated with COVID-19 in LTCFs that had least 1 case, even after controlling for county-level 
Table 1. Summary of LTCF Studies Reviewed

\begin{tabular}{|c|c|c|c|c|c|c|c|}
\hline Study & $\begin{array}{l}\text { No. } \\
\text { of } \\
\text { LTCFs }\end{array}$ & $\begin{array}{l}\text { Type of } \\
\text { LTCF }\end{array}$ & $\begin{array}{l}\text { Clinical } \\
\text { Data } \\
\text { Presented }^{\mathrm{a}}\end{array}$ & $\begin{array}{l}\text { Universal } \\
\text { Testing for } \\
\text { COVID-19 }\end{array}$ & $\begin{array}{l}\text { COVID-19 } \\
\text { Positivity } \\
\text { Rate, } \%^{\mathrm{b}}\end{array}$ & $\begin{array}{l}\text { Hospitalizations, } \\
\% / \text { Mortality } \%\end{array}$ & Locations \\
\hline Abrams et $\mathrm{al}^{23}$ & 9,395 & SNF & No & No & $\ldots$ & $-1-$ & $\begin{array}{l}\text { CA, CO, CT, DE, FL, GA, IA, IL, KY, LA, MA, MD, ME, } \\
\text { MI, MN, NC, ND, NJ, NM, NV, NY, OH, OK, OR, RI, SC, } \\
\text { TN, VT, WA, WV }\end{array}$ \\
\hline Arons et $\mathrm{al}^{9}$ & 1 & SNF & Yes & Yes & 64 & $-/ 26$ & King County, WA \\
\hline Blackman et $\mathrm{al}^{30}$ & 1 & SNF & No & No & $\ldots$ & $-1-$ & PA \\
\hline Blain et $\mathrm{al}^{10}$ & 1 & SNF & Yes & Yes & 48 & $-/ 32$ & France \\
\hline $\begin{array}{l}\text { Borras-Bermejo } \\
\text { et } \text { al }^{19}\end{array}$ & 69 & SNF & Yes & Yes & 23 & $-1-$ & Barcelona, Spain \\
\hline Dora et al $^{11}$ & 1 & SNF & Yes & Yes & 19 & $89 / 5$ & Los Angeles, CA \\
\hline Escobar et al ${ }^{12}$ & 1 & SNF & Yes & Yes & 37 & $-1-$ & PA \\
\hline Feaster et al $^{13}$ & 9 & SNF, ALF & Yes & Yes & 70 & $-1-$ & Pasadena, CA \\
\hline Graham et $\mathrm{al}^{14}$ & 4 & SNF & Yes & Yes & 40 & $-/ 17$ & London, UK \\
\hline Guery et $\mathrm{al}^{38}$ & 1 & SNF & Yes & Yes & $\cdots$ & $-1-$ & France \\
\hline Harrington et $\mathrm{al}^{26}$ & 272 & SNF & No & No & $\cdots$ & $-1-$ & CA \\
\hline He et $\mathrm{al}^{25}$ & 1,223 & SNF & No & No & $\ldots$ & $-1-$ & $\mathrm{CA}$ \\
\hline Li et $\mathrm{al}^{27}$ & 215 & SNF & No & No & $\cdots$ & $-1-$ & $\mathrm{CT}$ \\
\hline McMichael et $\mathrm{al}^{15}$ & 1 & SNF & Yes & No & 77 & $55 / 34$ & King County, WA \\
\hline Patel et $\mathrm{al}^{16}$ & 1 & SNF & Yes & Yes & 26 & $37 / 29$ & $\mathrm{IL}$ \\
\hline Roxby et al $^{18}$ & 1 & ALF & Yes & Yes & 4 & $3 / 1$ & King County, WA \\
\hline Rudolph et $\mathrm{al}^{20}$ & 134 & SNF & Yes & Yes & 6 & $-1-$ & United States \\
\hline Sanchez et al ${ }^{17}$ & 26 & SNF & Yes & Yes & 44 & $37 / 24$ & Detroit, MI \\
\hline Unruh et $\mathrm{al}^{24}$ & 1,162 & SNF & No & No & $\cdots$ & $-1-$ & $\mathrm{CT}, \mathrm{NJ}, \mathrm{NY}$ \\
\hline White et $\mathrm{al}^{21}$ & $3,357^{c}$ & SNF & No & Yes & 20 & $-1-$ & $\begin{array}{l}\text { AL, CA, CO, CT, KY, MA, MD, NH, NJ, NM, NV, PA, RI, } \\
\text { TN, VT, WA, WV }\end{array}$ \\
\hline
\end{tabular}

Note. LTCF, long-term care facility; SNF, skilled nursing facility; ALF, assisted-living facility; “..." and "_" indicate that data were not available for the corresponding entry.

${ }^{a}$ Yes = study presents data on prevalence of SARS-CoV-2, hospitalization rates, mortality rates, and/or symptoms of residents and/or staff. No = none of the data are presented.

${ }^{b}$ Positivity rate encompasses both attack rates and prevalence rates.

'69 of the 3,357 LTCFs underwent universal testing.

variables. ${ }^{27}$ White et $\mathrm{al}^{21}$ reported that county-level transmission was the strongest predictor of COVID-19 cases in LTCFs across 31 states: for every increase in 1,000 COVID-19 cases per 100,000 residents in any county, there was an associated $33.6 \%$ greater likelihood of COVID-19 cases in the facility. ${ }^{21}$

Eight studies evaluated the presence of comorbidities among LTCF resident with COVID-19 (Table 2). Residents with COVID-19 had high rates of hypertension, cardiac disease, diabetes, and cognitive impairment. ${ }^{9,11,12,15,18}$ Comparisons between COVID-19-positive and COVID-19-negative residents showed that renal disease $(P<.001)$, pulmonary disease $(P<.056)$, dementia $(P=.023)$, severe cognitive impairment $(P<.001)$, and obesity $(P=.026)$ were associated with SARS CoV-2 positivity. ${ }^{10,14,20}$ Furthermore, cardiovascular disease was strongly associated with increased mortality $\left(\chi^{2}=10.8 ; P=.001\right) .{ }^{14}$

\section{Clinical presentation}

Clinical presentation of COVID-19 can be variable in the LTCF population (Table 3). Four studies reported that between $69.7 \%$ and $93 \%$ of LTCF residents experienced typical COVID-19 symptoms such as fever, cough, dyspnea, or hypoxia. ${ }^{9,10,15,19}$ Other case reports have shown a high prevalence of fevers and cough alongside anorexia, headaches, diarrhea, and fatigue. ${ }^{11,16}$ Graham et $\mathrm{al}^{14}$ reported a strong association between anorexia, cough, and breathlessness and SARS-CoV-2 positivity. Given the low rate of fever among the elderly, it was not surprising that fever was not associated with increased odds of having a positive SARS-CoV-2 test. In fact, a study by Rudolph et $\mathrm{al}^{20}$ showed that only $26.6 \%$ of SARS$\mathrm{CoV}-2$ positive residents reached a fever of $38.0^{\circ} \mathrm{C}$ during their 28 day observation period. Neither anosmia or ageusia have been reported in the literature among this population.

Interestingly, typical COVID-19 symptoms were observed in SARS-CoV-2-negative residents, ranging from $10.6 \%$ to 54\%. ${ }^{9,10,14,18,19}$ Asymptomatic SARS-CoV-2 infections were also identified, with rates from $16 \%$ to $69.7 \% .{ }^{9,10,12-14,16,17,19}$ In studies by Arons et $\mathrm{al}^{9}$ and Escobar et $\mathrm{al}^{12}{ }^{12} 88 \%-92 \%$ of residents with asymptomatic infections developed symptoms during subsequent follow up. By contrast, Graham et $\mathrm{al}^{14}$ and Patel et $\mathrm{al}^{16}$ reported only $3 \%$ to $10 \%$ of asymptomatic infections developing subsequent symptoms among nursing-home residents.

\section{Prognosis}

Following COVID-19 diagnosis, many LTCF residents required subsequent hospitalization or expired (Table 1). The average hospitalization rate of SARS-CoV-2-positive residents across all studies was $44 \%$ and the average mortality rate was $21 \% .^{9-11,14-18}$ The 
Table 2. Comorbidities in LTCF Residents With COVID-19 in Reviewed Studies ${ }^{a}$

\begin{tabular}{|c|c|}
\hline Comorbidity $^{\mathrm{b}}$ & No. $(\%)$ \\
\hline Cancer & $\begin{array}{c}2(3)^{12} \\
15(14.9)^{15}\end{array}$ \\
\hline Cardiac disease & $\begin{array}{c}13(17)^{12} \\
102(23.0)^{20} \\
2(50)^{18} \\
199(50.5)^{14} \\
61(60.4)^{15} \\
12(63)^{11} \\
39(81)^{9} \\
32(84)^{10}\end{array}$ \\
\hline Cerebrovascular accident & $\begin{array}{c}5(6.5)^{12} \\
95(24.1)^{14} \\
10(26)^{10} \\
19(40)^{9}\end{array}$ \\
\hline Cognitive impairment & $\begin{array}{c}16(21)^{12} \\
28(58)^{9} \\
301(68.0)^{20} \\
32(84)^{10}\end{array}$ \\
\hline COPD & $\begin{array}{l}8(10)^{12} \\
4(21)^{11}\end{array}$ \\
\hline Dementia & $223(56.6)^{14}$ \\
\hline Diabetes mellitus & $\begin{array}{c}15(19)^{12} \\
92(23.4)^{14} \\
9(24)^{10} \\
32(31.7)^{15} \\
165(37.2)^{20} \\
18(38)^{9} \\
2(50)^{18} \\
11(58)^{11}\end{array}$ \\
\hline Hypertension & $\begin{array}{c}17(22)^{12} \\
68(67.3)^{15} \\
13(68)^{11} \\
309(69.8)^{20}\end{array}$ \\
\hline Immunological & $9(8.9)^{15}$ \\
\hline Liver disease & $6(5.9)^{15}$ \\
\hline Obesity & $\begin{array}{c}4(5)^{12} \\
101(22.8)^{20} \\
11(23)^{9} \\
1(25)^{18} \\
10(26)^{10} \\
31(30.7)^{15} \\
7(37)^{11}\end{array}$ \\
\hline Pulmonary disease & $\begin{array}{c}59(15)^{14} \\
9(24)^{10} \\
1(25)^{18} \\
32(31.7)^{15} \\
142(32)^{20} \\
18(38)^{9}\end{array}$ \\
\hline Received hemodialysis & $\begin{array}{c}1(1.3)^{12} \\
3(6)^{9}\end{array}$ \\
\hline Renal disease & $\begin{array}{c}3(4)^{12} \\
3(16)^{11} \\
86(21.8)^{14} \\
1(25)^{18} \\
18(38)^{9} \\
41(40.6)^{15} \\
26(68)^{10}\end{array}$ \\
\hline
\end{tabular}

Note. COPD, chronic obstructive pulmonary disease.

${ }^{a}$ Only studies that preset clinical data are listed.

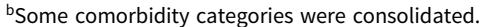

Table 3. Signs and Symptoms Among COVID-19 LTCF Residents in Reviewed Studies $^{\mathrm{a}}$

\begin{tabular}{|c|c|}
\hline Symptoms $^{b}$ & No. (\%) \\
\hline Typical $^{c}$ & $\begin{array}{c}211(30.7)^{19} \\
17(80.9)^{9}\end{array}$ \\
\hline Fever & $\begin{array}{c}118(26.6)^{20} \\
211(30.7)^{19 d} \\
30(41.7)^{14} \\
15(43)^{16} \\
27(74)^{10} \\
11(84.6)^{11}\end{array}$ \\
\hline Cough & $\begin{array}{c}1(25)^{18} \\
9(26)^{16} \\
211(30.7)^{19 d} \\
14(37)^{10} \\
7(53.9)^{11} \\
41(59.9)^{14 ~ e} \\
111(-)^{15 e}\end{array}$ \\
\hline Dyspnea & $\begin{array}{c}5(14)^{16} \\
3(23.1)^{11} \\
211(30.7)^{19 d} \\
41(59.9)^{14 e} \\
24(63)^{10} \\
111(-)^{15 e}\end{array}$ \\
\hline Hypoxia & $\begin{array}{c}1(3)^{16} \\
21(55)^{10}\end{array}$ \\
\hline Atypical $^{c}$ & $\begin{array}{l}6(16)^{10} \\
4(19)^{9}\end{array}$ \\
\hline Chills & $1(3)^{16}$ \\
\hline Malaise & $9(26)^{16}$ \\
\hline Sore throat & $3(9)^{16}$ \\
\hline Confusion & $43(59.7)^{14}$ \\
\hline Rhinorrhea & $\ldots$ \\
\hline Nasal congestion & $\ldots$ \\
\hline Myalgia & $\begin{array}{c}2(6)^{16} \\
1(7.7)^{11}\end{array}$ \\
\hline Dizziness & $\ldots$ \\
\hline Headache & $2(15.4)^{11}$ \\
\hline Nausea/Vomiting & $2(15.4)^{11}$ \\
\hline Diarrhea & $2(2.8)^{14}$ \\
\hline Decreased appetite & $\begin{array}{c}4(11)^{16} \\
4(30.8)^{11} \\
34(47.2)^{14}\end{array}$ \\
\hline Seizures & $1(3)^{16}$ \\
\hline LOC & $1(3)^{16}$ \\
\hline
\end{tabular}

Note. LTCF, long-term care facility; LOC, loss of consciousness; “. . . " indicates that data was not available for the corresponding entry.

anly studies that present clinical data are listed.

bome symptom categories were consolidated.

"Categories of "typical" and "atypical" are based on the CDC symptom categorization.

${ }^{\mathrm{d}}$ This study reported an aggregate incidence rate of fever, cough, and dyspnea.

${ }^{\mathrm{e}}$ These studies reported aggregate incidence rates of cough and dyspnea.

highest hospitalization rate was reported by Dora et $\mathrm{al}^{11}$ at $89 \%$; however, these researchers stated that transfers to acute-care settings were primarily driven early in the pandemic by the need 
Table 4. Containment Interventions Utilized by LTCF in Reviewed Studies ${ }^{\text {a }}$

\begin{tabular}{|c|c|c|}
\hline Study & Before Outbreak & After Outbreak \\
\hline Arons et $\mathrm{al}^{9}$ & $\begin{array}{l}\text { Daily resident symptom assessment, daily staff symptom } \\
\text { assessment }\end{array}$ & $\begin{array}{l}\text { Point prevalence testing of residents, point prevalence testing of staff, } \\
\text { restriction of visitation, }{ }^{b} \text { social distancing, }{ }^{c} \text { universal } \\
\text { transmission-based precautions, universal use of PPE }\end{array}$ \\
\hline Blackman et $\mathrm{al}^{30}$ & $\begin{array}{l}\text { Daily resident symptom assessment, daily staff symptom } \\
\text { assessment, infection control training, restriction of visita- } \\
\text { tion, }{ }^{b} \text { social distancing }\end{array}$ & $\begin{array}{l}\text { Cohorting of residents and staff, symptom-based testing of } \\
\text { residents, universal transmission-based precautions, universal use of } \\
\text { PPE }\end{array}$ \\
\hline Blain et $\mathrm{al}^{10}$ & $\cdots$ & Point prevalence testing of residents, point prevalence testing of staff \\
\hline $\begin{array}{l}\text { Borras-Bermejo } \\
\text { et } \mathrm{al}^{19}\end{array}$ & Restriction of visitation ${ }^{b}$ & $\begin{array}{l}\text { Cohorting of residents and staff, infection control training, point preva- } \\
\text { lence testing of residents, point prevalence testing of staff, social distan- } \\
\text { cingd }^{\text {d }}\end{array}$ \\
\hline Dora et $\mathrm{al}^{11}$ & $\begin{array}{l}\text { Daily resident symptom assessment, daily staff symptom } \\
\text { assessment, restriction of visitation }{ }^{b}\end{array}$ & $\begin{array}{l}\text { Cohorting of residents and staff, creation of COVID-19 ward, } \\
\text { infection control training, point prevalence testing of staff, serial testing } \\
\text { of residents, social distancing }{ }^{\mathrm{C}}\end{array}$ \\
\hline Escobar et al $^{12}$ & $\begin{array}{l}\text { Daily resident symptom assessment, daily staff symptom } \\
\text { assessment, point prevalence testing of staff, restriction of } \\
\text { visitation, }{ }^{\text {b }} \text { social distancing, }{ }^{c} \text { suspension of admissions, } \\
\text { use of metered inhalers vs nebulizers }\end{array}$ & $\begin{array}{l}\text { Cohorting of residents and staff, creation of COVID-19 ward, serial testing } \\
\text { of residents, universal use of PPE }\end{array}$ \\
\hline Feaster et $\mathrm{al}^{13}$ & $\cdots$ & $\begin{array}{l}\text { Cohorting of residents and staff, point prevalence testing of } \\
\text { residents, point prevalence testing of staff }\end{array}$ \\
\hline Graham et $\mathrm{al}^{14}$ & $\cdots$ & Point prevalence testing of residents, convenience testing of staff \\
\hline McMichael et $\mathrm{al}^{15}$ & $\cdots$ & Infection control training, symptom-based testing of residents \\
\hline Patel et $\mathrm{al}^{16}$ & $\cdots$ & $\begin{array}{l}\text { Cohorting of residents and staff, daily staff symptom assessment, infec- } \\
\text { tion control training, point prevalence testing of residents, point preva- } \\
\text { lence testing of staff, restriction of visitors, }{ }^{b} \text { universal masking of } \\
\text { residents, universal use of PPE }\end{array}$ \\
\hline Roxby et $a^{18}$ & $\cdots$ & $\begin{array}{l}\text { Daily staff symptom assessment, point prevalence testing of } \\
\text { residents, point prevalence testing of staff, social distancing }\end{array}$ \\
\hline Sanchez et $\mathrm{al}^{17}$ & Symptom-based testing of residents & $\begin{array}{l}\text { Cohorting of residents and staff, creation of COVID-19 ward, } \\
\text { infection control training, point prevalence testing of staff, serial testing } \\
\text { of residents }\end{array}$ \\
\hline
\end{tabular}

Note. LTCF, long-term care facility; PPE, personal protective equipment; “...” indicates that a containment intervention was not listed for the corresponding period.

a Only studies describing containment interventions are listed.

${ }^{b}$ All visitors restricted from entering the facility.

${ }^{c}$ Communal dining and activities cancelled.

${ }^{\mathrm{d}}$ Communal dining and activities cancelled but residents continued to share rooms.

to isolate these residents from others in the facility. The highest fatality rate reported to date was $33.7 \%$ in a 130 -bed LTCF in Washington State. ${ }^{15}$

\section{Containment interventions}

A wide array of interventions have been used by LTCFs to prevent and/or halt outbreaks of COVID-19 (Table 4). Surveillance and social distancing were used almost universally, with group activities cancelled and daily screening of residents, staff, and visitors effected. ${ }^{9,15}$ Visitation restrictions were also enacted upon recommendation of the CDC and CMS to prevent introduction of COVID-19 from the community into LTCFs. ${ }^{28,29}$ Although no studies have examined this issue directly, reports by Graham et $\mathrm{al}^{14}$ and Blackman et $\mathrm{al}^{30}$ show that, even with stringent visitation restrictions, COVID-19 can still be introduced to LTCFs. Once an outbreak occurred, cohorting was universally used in an attempt to mitigate the spread of COVID-19. However, due to limited supplies of SARS-CoV-2 rRT-PCR tests, universal testing among residents and staff was not performed, thereby limiting the effectiveness of cohorting interventions. ${ }^{30,31}$ As tests became more widely available and evidence emerged of asymptomatic transmission, universal testing during LTCF outbreaks was recommended. ${ }^{9,32}$ Cohorting and universal testing have proven effective; facilities in California and Illinois that utilized these methods saw a significant reduction in incidence and fatality rate when compared to earlier studies that did not use universal testing to guide cohorting. ${ }^{9,11,15,16,30}$ In May 2020, the CDC recommended that all nursing-home residents and healthcare workers (HCWs) should be tested if a case of COVID-19 is detected, followed by weekly testing of negative residents until no new cases are detected. ${ }^{33}$ Subsequent studies have reinforced the value of this approach. ${ }^{10,12,17}$

\section{Role of HCWs}

Nosocomial transmission in medical settings is often driven by HCWs unknowingly transmitting illnesses to the patients they care for. ${ }^{34}$ Given that HCWs have been found to be asymptomatic carriers of SARS-CoV-2, current recommendations stress the use of personal protective equipment to prevent viral spread within LTCFs. ${ }^{28,35,36}$ Three studies presented epidemiological evidence of such transmission. In a Pennsylvania LTCF, 2 HCWs who lived together but worked on different units concurrently tested positive for SARS-CoV-2, causing clusters of cases on their respective 
units. $^{30}$ In King County, Washington, interfacility spread of COVID-19 was facilitated via shared HCWs who worked at multiple facilities. ${ }^{15}$ In addition, genetic sequencing data collected during an outbreak in a London LTCF showed similar SARS-CoV-2 sequence data among a group of residents and a single HCW who cared for them. ${ }^{14}$

A prevalence study of SARS-CoV-2 infection among general practitioners and nurses from primary-care centers and nursing homes in León, Spain, reported that the prevalence of SARS$\mathrm{CoV}-2$ was higher in nursing homes than in primary-care centers (9.5\% vs $5.5 \%)$. However, no statistically significant differences were observed by sex, type of professional, level of exposure, or compliance with preventative measures. ${ }^{37}$ In other studies that measured COVID-19 prevalence among LTCF HCWs, values ranged from $2.2 \%$ to $62.6 \%{ }^{9}{ }^{9-13,15,16,18,19,38}$ Positive SARS-CoV-2 cases in LTCF studies included both frontline nursing staff as well as ancillary workers. Although most SARS-CoV-2-positive cases have occurred among LTCF nursing staff, other personnel, such as physicians, physical, speech and occupational therapists, case managers, health information officers, and environmental services, have also been affected. ${ }^{9,15}$

Identification of positive HCWs via symptom screening can be problematic because HCWs in LTCFs can be asymptomatic, with only $19 \%$ to $55.8 \%$ of staff exhibiting symptoms such as cough, fever, sore throat, dyspnea, headaches, or myalgias. ${ }^{9,16,18,19}$ Further complicating infection prevention measures, $9.75 \%$ to $40 \%$ of HCWs with negative SARS-CoV-2 test results had symptoms characteristic of COVID-19, and $4 \%$ to $55.8 \%$ were asymptomatic with a positive test. ${ }^{9,10,13,14,18,19,37,38}$

Many COVID-19 infection prevention measures are focused on staff use of personal protective equipment (PPE) and, therefore, can be hindered by shortages of these supplies. In a survey of US LTCFs early in the pandemic, $72 \%$ reported having inadequate access to PPE, $88 \%$ of surveyed facilities reporting a shortage of face shields, and $64 \%$ of surveyed facilities reporting a shortage of surgical masks. ${ }^{39}$ HCWs in LTCFs have continued to work despite having symptoms consistent with COVID-19. In a study of 50 HCWs who tested positive during the initial cluster of COVID19 in Washington State, 64\% reported working while exhibiting symptoms. $^{40}$

In conclusion, our review of recent studies and guidelines for COVID-19 in LTCFs has identified several key observations as well as areas for further investigation. First, emerging data indicate that certain facility characteristics are associated with increased likelihood of having at least 1 COVID-19 case in an LTCF: Five-Star rating, resident demographics, staffing levels, and county-level transmission. In addition, once SARS-CoV-2 is introduced into an LTCF, it can quickly spread, leading to high rates of morbidity, hospitalization, and mortality. Infection control interventions, such as cohorting and universal testing of staff and residents, appear to be effective. Many studies have indicated the effectiveness of these strategies to mitigate COVID-19 outbreaks. Given the disproportionate transmission, morbidity, and mortality in the nursing-home population, more studies are needed that incorporate novel containment interventions in LTCFs.

\section{Acknowledgments.}

Financial support. This work was supported by funding from the Advancing a Healthier Wisconsin Endowment (to A.H.W.).
Conflicts of interest. All authors report no conflicts of interest relevant to this article.

\section{References}

1. Archived: WHO Timeline-COVID-19. World Health Organization website. https://www.who.int/news-room/detail/27-04-2020-who-timelinecovid-19. Published 2020. Accessed July 30, 2020.

2. Huang C, Wang Y, Li X, et al. Clinical features of patients infected with 2019 novel coronavirus in Wuhan, China. Lancet 2020;395:497-506.

3. Onder G, Rezza G, Brusaferro S. Case-fatality rate and characteristics of patients dying in relation to COVID-19 in Italy. JAMA 2020;323:1775-1776.

4. Wu C, Chen X, Cai Y, et al. Risk factors associated with acute respiratory distress syndrome and death in patients with coronavirus disease 2019 pneumonia in Wuhan, China. JAMA Intern Med 2020;180:934-943.

5. Coronavirus disease 2019 (COVID-19) cases in the US Centers for Disease Control and Prevention website. https://www.cdc.gov/coronavirus/2019ncov/cases-updates/cases-in-us.html. Published 2020. Accessed July 30, 2020.

6. COVID-19 nursing home data. Centers for Medicare \& Medicaid Services website. https://data.cms.gov/stories/s/COVID-19-Nursing-Home-Data/ bkwz-xpvg/. Published 2020. Accessed July 30, 2020

7. Danis K, Fonteneau L, Georges S, et al. High impact of COVID-19 in longterm care facilities, suggestion for monitoring in the EU/EEA, May 2020. Euro Surveill 2020;25.

8. Burki T. England and Wales see 20,000 excess deaths in care homes. Lancet 2020;395:1602.

9. Arons MM, Hatfield KM, Reddy SC, et al. Presymptomatic SARS-CoV-2 infections and transmission in a skilled nursing facility. $N$ Engl J Med 2020;382:2081-2090.

10. Blain $\mathrm{H}$, Rolland $\mathrm{Y}$, Tuaillon E, et al. Efficacy of a test-retest strategy in residents and health care personnel of a nursing home facing a COVID-19 outbreak. J Am Med Dir Assoc 2020;21:933-936.

11. Dora AV, Winnett A, Jatt LP, et al. Universal and serial laboratory testing for SARS-CoV-2 at a long-term care skilled nursing facility for veterans-Los Angeles, California, 2020. Morb Mortal Wkly Rep 2020;69:651-655.

12. Escobar DJ, Lanzi M, Saberi P, et al. Mitigation of a COVID-19 outbreak in a nursing home through serial testing of residents and staff. Clin Infect Dis 2020. doi: $10.1093 /$ cid/ciaa1021.

13. Feaster M, Goh YY. High proportion of asymptomatic SARS-CoV-2 infections in 9 long-term care facilities, Pasadena, California, USA, April 2020. Emerg Infect Dis 2020;26.

14. Graham NSN, Junghans C, Downes R, et al. SARS-CoV-2 infection, clinical features and outcome of COVID-19 in United Kingdom nursing homes. $J$ Infect 2020. doi: 10.1016/j.jinf.2020.05.073.

15. McMichael TM, Currie DW, Clark S, et al. Epidemiology of COVID-19 in a long-term care facility in King County, Washington. $N$ Engl J Med 2020;382:2005-2011.

16. Patel MC, Chaisson LH, Borgetti S, et al. Asymptomatic SARS-CoV-2 infection and COVID-19 mortality during an outbreak investigation in a skilled nursing facility. Clin Infect Dis 2020. doi: 10.1093/cid/ciaa763.

17. Sanchez GV, Biedron C, Fink LR, et al. Initial and repeated point prevalence surveys to inform SARS-CoV-2 infection prevention in 26 skilled nursing facilities-Detroit, Michigan, March-May 2020. Morb Mortal Wkly Rep 2020;69:882-886.

18. Roxby AC, Greninger AL, Hatfield KM, et al. Outbreak investigation of COVID-19 among residents and staff of an independent and assisted living community for older adults in Seattle, Washington. JAMA Intern Med 2020. doi: 10.1001/jamainternmed.2020.2233.

19. Borras-Bermejo B, Martínez-Gómez X, San Miguel MG, et al. Asymptomatic SARS-CoV-2 infection in nursing homes, Barcelona, Spain, April 2020. Emerg Infect Dis 2020;26:2281-2283.

20. Rudolph JL, Halladay CW, Barber M, et al. Temperature in nursing home residents systematically tested for SARS-CoV-2. J Am Med Dir Assoc 2020;21:895-899. 
21. White EM, Kosar CM, Feifer RA, et al. Variation in SARS-CoV-2 prevalence in US skilled nursing facilities. J Am Geriatr Soc 2020. doi: 10.1111/jgs. 16752.

22. Five-star quality rating system. Centers for Medicare \& Medicaid Services website. https://www.cms.gov/Medicare/Provider-Enrollmentand-Certification/CertificationandComplianc/FSQRS. Published 2020. Accessed August 3, 2020.

23. Abrams HR, Loomer L, Gandhi A, Grabowski DC. Characteristics of US nursing homes with COVID-19 cases. J Am Geriatr Soc 2020. doi: 10. 1111/jgs.16661.

24. Unruh MA, Yun H, Zhang Y, Braun RT, Jung HY. Nursing home characteristics associated with COVID-19 deaths in Connecticut, New Jersey, and New York. J Am Med Dir Assoc 2020;21:1001-1003.

25. He M, Li Y, Fang F. Is there a link between nursing home reported quality and COVID-19 cases? Evidence from California skilled-nursing facilities. J Am Med Dir Assoc 2020;21:905-908.

26. Harrington C, Ross L, Chapman S, Halifax E, Spurlock B, Bakerjian D. Nurse staffing and coronavirus infections in California nursing homes. Policy Polit Nurs Pract 2020. doi: 10.1177\%2F1527154420938707.

27. Li Y, Temkin-Greener H, Gao S, Cai X. COVID-19 infections and deaths among Connecticut nursing home residents: facility correlates. $\mathrm{J} \mathrm{Am}$ Geriatr Soc 2020. doi: 10.1111/jgs.16689.

28. Interim infection prevention and control recommendations for healthcare personnel during the coronavirus disease 2019 (COVID-19) pandemic. Centers for Disease Control and Prevention website. https://www.cdc. gov/coronavirus/2019-ncov/hcp/infection-control-recommendations. html. Published 2020. Accessed July 8, 2020.

29. Nursing Home Reopening Recommendations for State and Local Officials. Centers for Medicare \& Medicaid Services website. https://www. $\mathrm{cms}$.gov/medicareprovider-enrollment-and-certificationsurveycertifi cationgeninfopolicy-and-memos-states-and/nursing-home-reopeningrecommendations-state-and-local-officials. Published 2020. Accessed July 7, 2020.

30. Blackman C, Farber S, Feifer RA, Mor V, White EM. An illustration of SARS-CoV-2 dissemination within a skilled nursing facility using heat maps. J Am Geriatr Soc 2020. doi: 10.1111/jgs.16642.
31. Shear GA, Kaplan S, Fink S, Thomas K, Weiland N. The lost month: how a failure to test blinded the U.S. to COVID-19. New York Times website. https://www.nytimes.com/2020/03/28/us/testing-coronavirus-pandemic. html. Published 2020. Accessed August 5, 2020.

32. Wei WE, Li Z, Chiew CJ, Yong SE, Toh MP, Lee VJ. Presymptomatic transmission of SARS-CoV-2-Singapore, January 23-March 16, 2020. Morb Mortal Wkly Rep 2020;69:411-415.

33. Testing individuals: interim SARS-CoV-2 testing guidelines for nursing home residents and healthcare personnel. Centers for Disease Control and Prevention website. https://www.cdc.gov/coronavirus/2019-ncov/ hcp/nursing-homes-testing.html. Published 2020. Accessed August 1, 2020.

34. Vos MC. The healthcare worker as a source of transmission. In: Memish ZA. Guide To Infection Control In the Healthcare Setting. International Society For Infectious Diseases website. https://isid.org/guide/infectionprevention/ healthcareworker/. Published 2020. Accessed August 5, 2020.

35. Contejean A, Leporrier J, Canouï E, et al. Comparing dynamics and determinants of SARS-CoV-2 transmissions among healthcare workers of adult and pediatric settings in central Paris. Clin Infect Dis 2020. doi: 10.1093/cid/ ciaa977.

36. Mani NS, Budak JZ, Lan KF, et al. Prevalence of COVID-19 infection and outcomes among symptomatic healthcare workers in Seattle, Washington. Clin Infect Dis 2020. doi: 10.1093/cid/ciaa761.

37. Martín V, Fernández-Villa T, Lamuedra Gil de Gomez M, et al. Prevalence of SARS-CoV-2 infection in general practitioners and nurses in primary care and nursing homes in the Healthcare Area of León and associated factors. Semergen 2020;46:35-39.

38. Guery R, Delaye C, Brule N, et al. Limited effectiveness of systematic screening by nasopharyngeal RT-PCR of medicalized nursing home staff after a first case of COVID-19 in a resident. Med Mal Infect 2020. doi: 10.1016/ j.medmal.2020.04.020.

39. Quigley DD, Dick A, Agarwal M, Jones KM, Mody L, Stone PW. COVID-19 preparedness in nursing homes in the midst of the pandemic. J Am Geriatr Soc 2020;6:1164-1166.

40. Chow EJ, Schwartz NG, Tobolowsky FA, et al. Symptom screening at illness onset of health care personnel with SARS-CoV-2 infection in King County, Washington. JAMA 2020;323:2087-2089. 